\title{
Do Not Let Your Experiences Gather Dust
}

\author{
काe \\ Jessica Inch \\ Editor-in-Chief
}

C

hanges in the way nurses are educated means that we are increasingly expected to attend postgraduate courses associated with our places of work. This, in turn, has meant that the numbers of individuals taking places on Degree, Masters and $\mathrm{PhD}$ programmes have also increased. Think about this for a minute. How many coursework pieces, dissertations and theses are sitting on university databases and on dusty bookshelves in your spare rooms as part of these courses.

Many who have undertaken Masters and $\mathrm{PhD}$ programmes will already have been encouraged to think about publication of their work as part of this process. However, my personal experience is that this is usually the last thing that a nurse in any area thinks of once they have received their results from an academic course. It gets filed away in relief, not to see the light of day for a long time. Do we also do this with all our newly found knowledge gained at great expense to our own personal time and that of the unit in which we work, not to mention the finance? Hopefully not, as we are encouraged to integrate that knowledge into our practice immediately and share it with our colleagues and undergraduate students. Why do we not feel the same about our written work. Many students produce work worthy of publication every year and these are left to fester in boxes as they are either unaware of its potential or simply do not know how to start the process or whom to contact.

So, here it is, your golden opportunity to start that process. It could not be easier to send your completed course work to me here at Barna and get that ball rolling. Remember, you can even get in contact to discuss a future piece or even if you want pointers on an existing piece. Just contact me, the Editor, by email at jessicainchbarna@googlemail.com.

Good Luck... 